\title{
COOPERATIVAS AGROPECUÁRIAS E O DESAFIO DA SUCESSÃO NA AGRICULTURA FAMILIAR
}

\author{
L. M. DREBES ${ }^{1}$, R. M. SPANEVELLO ${ }^{2}$ \\ ${ }^{1,2}$ Universidade Federal de Santa Maria (UFSM), Campus Palmeira das Missões \\ drebesIm@gmail.com \\ Submetido 03/03/2016 - Aceito 04/06/2017 \\ DOI: $10.15628 /$ holos. 2017.4210
}

\section{RESUMO}

O estudo visa analisar as contribuições das cooperativas agropecuárias sobre a sucessão nos estabelecimentos agropecuários familiares. Foi conduzido como estudo de casos amostrados através de critérios institucionais e geográficos, envolvendo oito cooperativas. Os dados foram coletados com entrevistas junto aos dirigentes e jovens rurais vinculados com as organizações. Também foram utilizadas fontes documentais. Esses dados foram submetidos à análise de conteúdo. Notou-se interesse das cooperativas agropecuárias sobre a sucessão, com o desenvolvimento de ações voltadas a condicionantes socioeconômicas significantes aos jovens rurais. Embora os resultados alcançados sejam tímidos, a contribuição das cooperativas agropecuárias mostrou-se relevante à sucessão na agricultura familiar.

PALAVRAS-CHAVE: Juventude rural, reprodução social, migração, assistência técnica.

\section{AGRICULTURAL COOPERATIVES AND THE CHALLENGE OF SUCCESSION IN FAMILY FARMING}

\begin{abstract}
The study aims to analyze the contributions of the agricultural cooperatives on the succession in family agricultural establishments. It was conducted for the case studies shown by institutional and geographical criteria, involving eight cooperatives. The data were collected through interviews with leaders and young rural linked to organizations. Also documentary sources
\end{abstract}

were used. These data were subjected to content analysis. It was noted interest of agricultural cooperatives on the succession, with the development of actions directed to socio-economic conditions significant for young rural. Although the results obtained are shy, the contribution of agricultural cooperatives proved relevant to the succession in family farming.

KEYWORDS: Rural youth, social reproduction, migration, technical assistance. 


\section{INTRODUÇÃO}

No Brasil, desde sua consolidação em meados da década de 1990, a agricultura familiar tem sido considerada com relevância em termos econômicos, sociais e culturais. Em virtude disso, suas "crises" causam alvoroço entre cientistas, extensionistas, administradores e até mesmo civis. Conforme Renk e Cabral (2002), as crises indicam um cenário de ruína da condição de agricultor familiar, sendo originárias em uma infinidade de condicionantes socioeconômicas, cuja combinação resulta na inviabilidade de reprodução social e de autonomia através de estratégias até então conhecidas. Além disso, essas crises exibem caráter coletivo, atingindo não somente um ou outro agricultor familiar em certo contexto, mas todos.

Associadas a essas crises encontram-se as migrações, sobretudo de jovens rurais, e a concludente escassez de sucessores nos estabelecimentos agropecuários familiares (Renk \& Cabral, 2002). Conforme Drebes (2014), os jovens rurais são resistentes a continuar residindo no meio rural e trabalhando na agricultura, sendo muito vulneráveis às migrações. Entre as décadas de 1960 e de 1980, aproximadamente 27 milhões de brasileiros migraram de áreas rurais rumo a áreas urbanas, sobretudo jovens, entre os quais as moças eram mais proeminentes que os rapazes, configurando um êxodo rural seletivo e uma agricultura familiar esvaziada, envelhecida e masculinizada (Camarano \& Abramovay, 1998).

Em virtude desses indicativos de crise sucessória na agricultura familiar, muitos cientistas desenvolveram relevantes estudos sobre os jovens rurais, como Abramovay (1998), Carneiro (1999), Silvestro (2001), Stropasolas (2003), Brumer (2004), Gaviria e Menasche (2006), Spanevello (2008), Weisheimer (2009), Castro (2009), entre outros. Esses estudos estiveram concentrados sobre as condicionantes socioeconômicas relacionadas com a não ocorrência de sucessão e com a ocorrência de migração. Dessa maneira, os embaraços à constituição das novas gerações de agricultores familiares encontram-se devidamente indicados. Contudo, é necessário avançar nas inferências sobre a sucessão, analisando como minimizar ou, ainda, vencer esses obstáculos, auxiliando a continuidade dos estabelecimentos agropecuários familiares através da manutenção dos jovens no âmbito da agricultura familiar.

Curiosamente, entre as condicionantes socioeconômicas destacadas nos estudos anteriores encontra-se o estímulo de organizações de assistência técnica e extensão rural. Em meio a essas organizações, a ênfase recai sobre as cooperativas agropecuárias em virtude de sua natureza socioeconômica e intimidade com os agricultores familiares. Nesse sentido, e considerando a necessidade de renovação de seus cooperados, acredita-se na vocação das cooperativas agropecuárias em cativar sucessores aos estabelecimentos agropecuários familiares, minimizando as migrações entre os jovens rurais. Assim, esse estudo visa analisar as contribuições das cooperativas agropecuárias sobre a sucessão nos estabelecimentos agropecuários familiares.

\section{METODOLOGIA}

O estudo foi realizado com as oito cooperativas agropecuárias filiadas à Federação das Cooperativas Agropecuárias do Rio Grande do Sul (FECOAGRO) situadas na região Alto Jacuí, sendo elas: Cooperativa Tritícola Espumoso Ltda. (COTRIEL), Cooperativa Agrícola Mista General Osório Ltda. (COTRIBÁ), Cotrijal Cooperativa Agropecuária e Industrial (COTRIJAL), Cotripal Agropecuária Cooperativa (COTRIPAL), Cooperativa Tritícola Sarandi Ltda. (COTRISAL), Cooperativa Agrícola Soledade Ltda. (COAGRISOL), Cooperativa Tritícola Taperense Ltda. (COTRISOJA) e Cooperativa dos 
Agricultores de Chapada Ltda. (COAGRIL). A localização das mesmas encontra-se ilustrada na Figura 01.

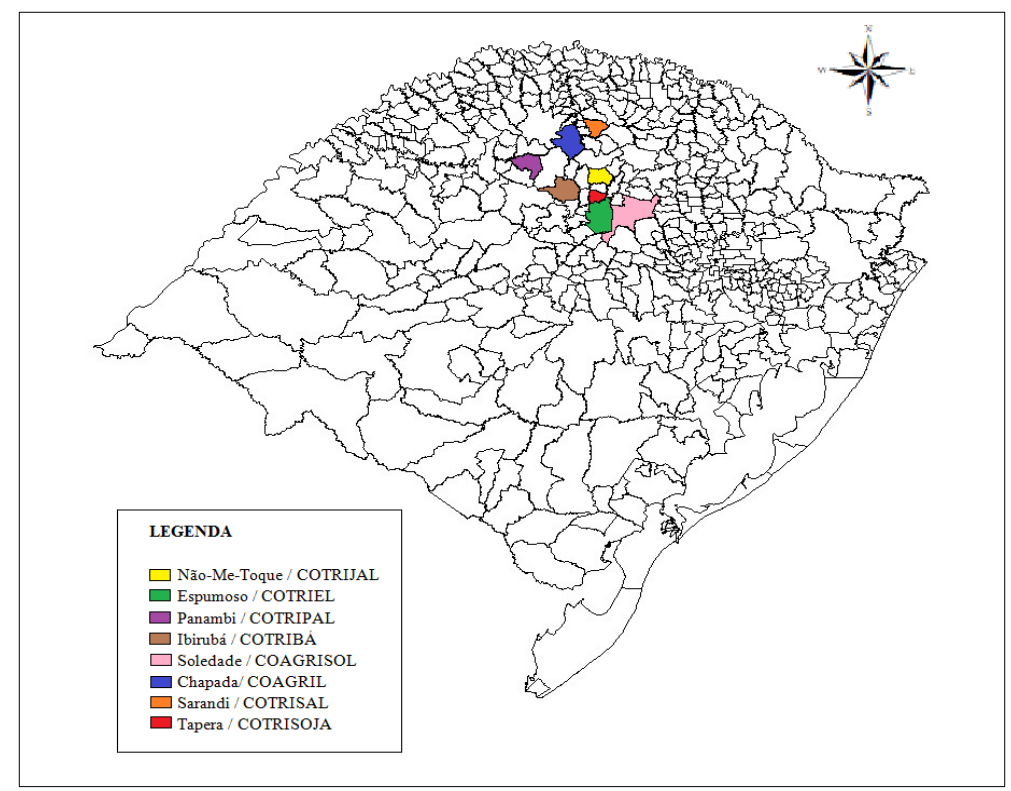

Figura 01 - Localização das cooperativas agropecuárias estudadas no Alto Jacuí, Rio Grande do Sul, Brasil. Fonte: as autoras.

Dessa maneira, esse consiste em um estudo de oito casos amostrados através de critérios institucionais (filiação à entidade FECOAGRO) e geográficos (localização na região Alto Jacuí), como orienta Poupart et. al. (2010). Esses critérios fundamentaram-se na representatividade da entidade FECOAGRO em relação aos interesses do cooperativismo agropecuário no Rio Grande do Sul e na existência de algumas das maiores cooperativas agropecuárias gaúchas na região Alto Jacuí em termos de relevância socioeconômica. As características das organizações estudadas encontram-se resumidas no Quadro 01.

\begin{tabular}{|c|c|c|c|c|}
\hline Cooperativa & Fundação & Sede & Abrangência & Cooperados \\
\hline COTRIBÁ & 1911 & Ibirubá & $\begin{array}{c}\text { Quinze de Novembro, Fortaleza dos Valos, } \\
\text { Boa Vista do Incra, Tupanciretã, Cruz Alta, } \\
\text { Santa Bárbara do Sul, Saldanha Marinho, } \\
\text { São Gabriel, Santa Margarida do Sul, Rio } \\
\text { Pardo, Pântano Grande, Butiá, Encruzilhada } \\
\text { do Sul, Cachoeira do Sul e Candelária }\end{array}$ & 5.500 \\
\hline COTRISAL & 1957 & Sarandi & $\begin{array}{c}\text { Barra Funda, Cerro Grande, Chapada, } \\
\text { Constantina, Engenho Velho, Gramado dos } \\
\text { Loureiros, Liberato Salzano, Almirante } \\
\text { Tamandaré do Sul, Nonoai, Nova Boa Vista, } \\
\text { Novo Barreiro, Novo Xingu, Palmeira das } \\
\text { Missões, Pontão, Rio dos Índios, Ronda Alta, } \\
\text { Rondinha, Sagrada Família, São José das } \\
\text { Missões, Seberi, Três Palmeiras e Trindade } \\
\text { do Sul }\end{array}$ & 9.130 \\
\hline COTRIPAL & 1957 & Panambi & $\begin{array}{r}\text { Condor, Pejuçara, Santa Bárbara do Sul e } \\
\text { Ajuricaba }\end{array}$ & 3.368 \\
\hline
\end{tabular}




\begin{tabular}{|c|c|c|c|c|}
\hline COTRIJAL & 1957 & $\begin{array}{c}\text { Não-Me- } \\
\text { Toque }\end{array}$ & $\begin{array}{c}\text { Colorado, Victor Graeff, Tio Hugo, Lagoa dos } \\
\text { Três Cantos, Almirante Tamandaré do Sul, } \\
\text { Carazinho, Santo Antônio do Planalto, } \\
\text { Coqueiros do Sul, Saldanha Marinho, } \\
\text { Nicolau Vergueiro, Ernestina, Passo Fundo e } \\
\text { Mato Castelhano }\end{array}$ & 5.236 \\
\hline COTRIEL & 1959 & Espumoso & $\begin{array}{c}\text { Salto do Jacuí, Alto Alegre, Campos Borges, } \\
\text { Estrela Velha, Arroio do Tigre, Rio Pardo, } \\
\text { Sobradinho e Pântano Grande }\end{array}$ & 5.772 \\
\hline COTRISOJA & 1966 & Tapera & $\begin{array}{c}\text { Selbach, Lagoa dos Três Cantos e Victor } \\
\text { Graeff }\end{array}$ & 1.969 \\
\hline COAGRISOL & 1969 & Soledade & $\begin{array}{c}\text { Barros Cassal, Gramado Xavier, Progresso, } \\
\text { Arvorezinha, Itapuca, Nova Alvorada, } \\
\text { Camargo, Ibirapuitã, Nicolau Vergueiro, Tio } \\
\text { Hugo, Tunas, Mormaço, Lagoão, Jacuizinho, } \\
\text { Fontoura Xavier, Marau, Santo Antônio do } \\
\text { Palma, Lagoa Vermelha, Vila Maria, Casca, } \\
\text { Gentil e São José do Herval }\end{array}$ & 10.465 \\
\hline COAGRIL & 1986 & Chapada & Novo Barreiro & 1.517 \\
\hline
\end{tabular}

Quadro 01 - Caracterização das cooperativas agropecuárias estudadas. Fonte: as autoras.

Os dados foram coletados através da técnica de entrevista com roteiro semiestruturado, em momentos diferenciados. Segundo Gil (2011), esse roteiro é capaz de conferir certa flexibilidade ao desenvolvimento da entrevista e se caracteriza por uma estruturação mínima atribuída através de uma relação de pontos de interesse ordenados e relacionados, os quais conduzem o desenvolvimento da mesma. Na fase inicial, entrevistaram-se os representantes das cooperativas agropecuárias envolvidas no estudo, isto é, COTRIBÁ, COTRISAL, COTRIPAL, COTRIJAL, COTRIEL, COTRISOJA, COAGRISOL e COAGRIL, contabilizando 8 entrevistas, uma em cada cooperativa agropecuária.

$\mathrm{Na}$ fase final, foram realizadas entrevistas com jovens agricultores cooperados e/ou filhos de agricultores cooperados considerados sucessores ou prováveis sucessores dos estabelecimentos agropecuários familiares. Em concordância com as informações coletadas na fase anterior, essas entrevistas foram realizadas somente nas cooperativas agropecuárias com ações direta ou indiretamente direcionadas à sucessão na agricultura familiar, sendo elas COTRIPAL, COTRIJAL, COTRISAL e COAGRISOL. No total, realizaram-se 16 entrevistas com jovens rurais. As características desses entrevistados constam na Tabela 01.

\begin{tabular}{lcc}
\hline Jovens & \multicolumn{3}{c}{ Frequência } \\
& $\mathrm{Fa}$ & $\mathrm{Fr}$ \\
Idade & (n) & (\%) \\
$<20$ anos & 3 & \\
$20-29$ anos & 9 & 18,7 \\
$>29$ anos & 4 & 56,3 \\
Gênero & & 25,0 \\
Feminino & 1 & \\
Masculino & 15 & 6,2 \\
Estado civil & & 93,8
\end{tabular}




\begin{tabular}{lcc} 
Solteiro & 11 & 68,7 \\
Casado & 5 & 31,3 \\
Grau de escolaridade & 1 & \\
Ensino Médio Incompleto & 10 & 6,2 \\
Ensino Médio Completo & 4 & 62,6 \\
Ensino Superior Incompleto & 1 & 25,0 \\
Ensino Superior Completo & & 6,2 \\
Residência & 14 & 87,6 \\
Estabelecimento dos pais & 1 & 6,2 \\
Estabelecimentos dos sogros & 1 & 6,2 \\
Estabelecimentos separados & & \\
Relação com cooperativa & 12 & 75,0 \\
Associado & 2 & 12,5 \\
Não associado & 2 & 12,5 \\
Não informado & & \\
Profissão & 13 & 81,3 \\
Agricultor & 2 & 12,5 \\
Agricultor e estudante & 1 & 6,2 \\
Agricultora e dona de casa & 16 & 100 \\
\hline Total & &
\end{tabular}

Tabela 01 - Caracterização dos jovens rurais entrevistados. Fonte: as autoras.

A Tabela 01 evidencia que o perfil dos jovens rurais entrevistados consiste em: homens (93,8\%), solteiros $(68,7 \%)$, com idade entre 20 e 29 anos (56,3\%), residentes nos estabelecimentos rurais dos pais $(87,6 \%)$ e associados às cooperativas agropecuárias $(75,0 \%)$, cuja escolaridade é o Ensino Médio Completo (62,6\%) e cuja profissão é a agricultura (81,3\%).

Complementarmente, também foram coletados dados através de fontes documentais, como os sites, os jornais, entre outros documentos vinculados às cooperativas, e as séries estatísticas históricas vinculadas às áreas rurais estudadas (Gil, 2011). Os dados coletados foram organizados, sistematizados e analisados através da metodologia de análise de conteúdo, envolvendo descrições, inferências e interpretações (Bardin, 2011).

\section{REVISÃO BIBLIOGRÁFICA}

3.1 Reprodução social através da sucessão na agricultura familiar: os jovens rurais e as cooperativas agropecuárias

De acordo com Bourdieu (2011), a reprodução social refere-se às relações constituintes da ordenação das sociedades, sendo essa ordem social relacionada com a manutenção e a sustentação de ações de construção e reconstrução de suas estruturas "objetivas", ou seja, os capitais, e de suas estruturas "subjetivas", isto é, os habitus. Contudo, ao contrário do que se possa imaginar, a reprodução social não se restringe a uma mera conservação da estrutura do grupo através do consenso entre os capitais e os habitus em campo, mas envolve, também, a transformação de sua estrutura por meio do dissenso existente entre os mesmos. 
Considerando a reprodução social no âmbito das famílias, Bourdieu (2011) elenca uma série de estratégias sistematicamente relacionadas e utilizadas em diferentes momentos do ciclo de vida das mesmas, segundo um processo irreversível e cronologicamente articulado. Algumas são de curto e outras de longo prazo, estando agrupadas em estratégias biológicas, educativas, de investimento social, de investimento econômico, de investimento simbólico e de sucessão.

Em relação a essas últimas, ou seja, às estratégias sucessórias, as mesmas intencionam transmitir a herança (isto é, repassar capitais e perpetuar habitus) entre gerações sucessivas com o mínimo de avaria dentro dos limites oferecidos, recorrendo, ainda, a artifícios e subterfúgios encontrados. As estratégias sucessórias variam conforme a herança transmitida (Bourdieu, 2011).

Se tratando de famílias rurais, Bourdieu (2012a) indica contradições inerentes à sucessão em virtude de suas características únicas. Conforme Lamarche (1993), a agricultura familiar remete à íntima relação entre terra, trabalho e família. Nesse sentido, Bourdieu (2012b) evidencia como a inexistência de sucessores significa o encerramento dos estabelecimentos agropecuários familiares, ocasionando efeitos econômicos, sociais e culturais, interrompendo a transmissão da herança.

A partida do herdeiro sinaliza a parada mortal da empresa agrícola - tendo-se mostrado que ela deve suas particularidades mais marcantes ao fato que a reprodução biológica, portanto, de sua força de trabalho, faz parte das condições de sua reprodução [...]. O filho que se recusa a se fazer herdeiro da herança paterna consuma um 'assassinato do pai' bem mais terrível do que aquele que consiste em tomar o seu lugar, sucedê-lo [...]. Ele anula não somente a aceitação paterna, sua submissão à tradição da herança, mas, tratando-se de uma herança que é quase inteiramente o produto de quem a transmite, ele anula também sobretudo a obra paterna, essa obra de toda uma vida. Ele coloca seu pai diante de um dilema tão insuportável que este não pode lembrá-lo senão num discurso que, por seus silêncios, suas circunlocuções, suas atenuações, suas dissimulações e suas contradições, visa tanto encobri-lo quanto descobri-lo [...] (Bourdieu, 2012b, p. 440).

$\mathrm{Na}$ agricultura familiar, até meados do século $\mathrm{XX}$, as estratégias sucessórias eram utilizadas com sucesso. Sendo assim, os filhos dos agricultores também se tornavam agricultores (Champagne, 1986). Todavia, com o advento da modernização da agricultura esse cenário se transformou no mundo inteiro.

No Brasil essas mudanças iniciaram, sobretudo, na década de 1960. De acordo com Spanevello (2008), em estudo realizado no estado do Rio Grande do Sul, a modernização da agricultura acentuou uma série de condicionantes socioeconômicas desfavoráveis à consolidação da sucessão na agricultura familiar. Para Spanevello (2008), entre as inúmeras condicionantes socioeconômicas relevantes na sucessão, sejam elas internas ou externas aos estabelecimentos agropecuários, os jovens rurais costumam destacar: renda, autonomia, acesso à terra, relacionamento intrafamiliar, valorização do trabalho na agricultura e da vida no meio rural, escolarização, acesso a lazer, envolvimento em movimentos sociais, círculos socioafetivos no meio rural, acesso a crédito e políticas públicas, acesso a organizações de fomento técnico e extensão rural, entre outros.

Atentando à condicionante de acesso a organizações de fomento técnico e extensão rural, a ênfase recai sobre as cooperativas agropecuárias, tendo em vista sua intimidade com os agricultores e sua atuação em âmbito socioeconômico, melhorando as condições de vida dos cooperados e, assim, facilitando a ocorrência da sucessão. As cooperativas agropecuárias são como uma extensão dos estabelecimentos agropecuários familiares, oferecendo crédito, 
assistência técnica, insumos, canais de comercialização, entre outros serviços variados (Spanevello \& Lago, 2006).

No entanto, conforme Leitzke e Santos (2013), em estudo realizado no Noroeste do Rio Grande do Sul, somente em torno de $7 \%$ dos jovens rurais, filhos de agricultores familiares, estão inseridos na administração de cooperativas vinculadas com a economia solidária. É um número reduzido, tendo em vista que praticamente $93 \%$ desses jovens rurais estudados identificaram as cooperativas como úteis à concretização de seus projetos de vida.

É importante salientar, ainda com base no estudo de Leitzke e Santos (2013), que 62\% dos jovens rurais não reconheceram ações no sentido de incentivar sua continuação nos estabelecimentos rurais familiares como sucessores, mas reconheceram muitas ações voltadas ao crescimento socioeconômico dos cooperados, através dos serviços de assistência técnica, estímulos à produção e auxílios na comercialização. Entre as ações requeridas, os jovens constataram a necessidade de incentivos à permanência no campo, a realização de cursos, palestras e capacitações em cooperativismo, dias de campo e atividades de lazer.

Contudo, as ações de crescimento socioeconômico podem ser decisivas no fomento à sucessão. O estudo de Boessio (2015), analisando as colocações da direção e da assistência técnica de uma cooperativa agropecuária em Minas Gerais, constatou seu envolvimento em ações de capacitação e de informação, induzindo tecnologias facilitadoras ao trabalho na agricultura, tendo as mesmas efeitos estimulantes à continuidade dos jovens nos estabelecimentos rurais familiares. Para Boessio (2015) o discurso disseminado por dirigentes e por técnicos visou mostrar como as áreas rurais oferecem atividades econômicas mais rentáveis e menos estafantes do que em épocas passadas, imprimindo um efeito positivo à permanência dos jovens. Outro incentivo consistiu em valorizar o filho do cooperado, delegando determinadas atividades ou repassando conhecimentos técnicos específicos aos mesmos, garantindo, assim, a sua autonomia na execução de algumas atividades no interior dos estabelecimentos rurais familiares. Ademais, incitamentos como bolsas de estudos para formação na área técnica agropecuária também foram vistos como positivos.

Quanto mais efetivo o atendimento dessas organizações às necessidades dos estabelecimentos agropecuários familiares e, sobretudo, dos jovens rurais considerados futuros sucessores, acredita-se na maior influência sobre a concretização da sucessão (Spanevello \& Lago, 2006).

\section{RESULTADOS E DISCUSSÃO}

4.1 As motivações das cooperativas agropecuárias em auxiliar a sucessão na agricultura familiar

Todas as cooperativas agropecuárias estudadas se mostraram motivadas em relação à temática da sucessão na agricultura familiar. Suas motivações são claras: sem sucessão não existem novos agricultores e não ocorre a renovação entre os cooperados. Assim, essas organizações estão "amarradas" à continuidade dos estabelecimentos agropecuários familiares dos cooperados através da sucessão, ou seja, da manutenção das novas gerações no meio rural e na agricultura. A sobrevivência das cooperativas agropecuárias exige a sobrevivência dos estabelecimentos agropecuários familiares.

Esses vínculos são mais incisivos, sobretudo, com os agricultores familiares se comparados aos patronais. Os mesmos constituem o segmento mais ativo entre os cooperados, necessitando 
auxílio das cooperativas em resistir aos riscos e estabilizar seus rendimentos (Bialoskorski Neto, 2007). Sendo assim, é sobre a sucessão na agricultura familiar onde estão concentradas as motivações das cooperativas agropecuárias. Esse viés é encontrado no relato do representante da cooperativa COTRISOJA, evidenciado abaixo.

\begin{abstract}
O que vai sumir são as pequenas propriedades. 0 grande problema é que o jovem não quer participar, a gente tem que achar uma forma de trazer os jovens, colocar em algum lugar e discutir, e botar na cabeça deles como deveria ser, como deve funcionar. [...] Qual é o jovem que ainda está no interior? Será que essa geração que está com 18, 20, 25 anos... será que essa geração vai ficar? (Representante COTRISOJA).
\end{abstract}

Os receios das cooperativas agropecuárias do Alto Jacuí frente à sucessão na agricultura familiar se maximizam ao considerar os dados dos Censos Demográficos de 2000 e 2010 do Instituto Brasileiro de Geografia e Estatística (IBGE). Os recenseamentos mostram significativas reduções entre os jovens residentes nas áreas rurais dos municípios onde se encontram as sedes das cooperativas agropecuárias estudadas, como consta na Figura 02.

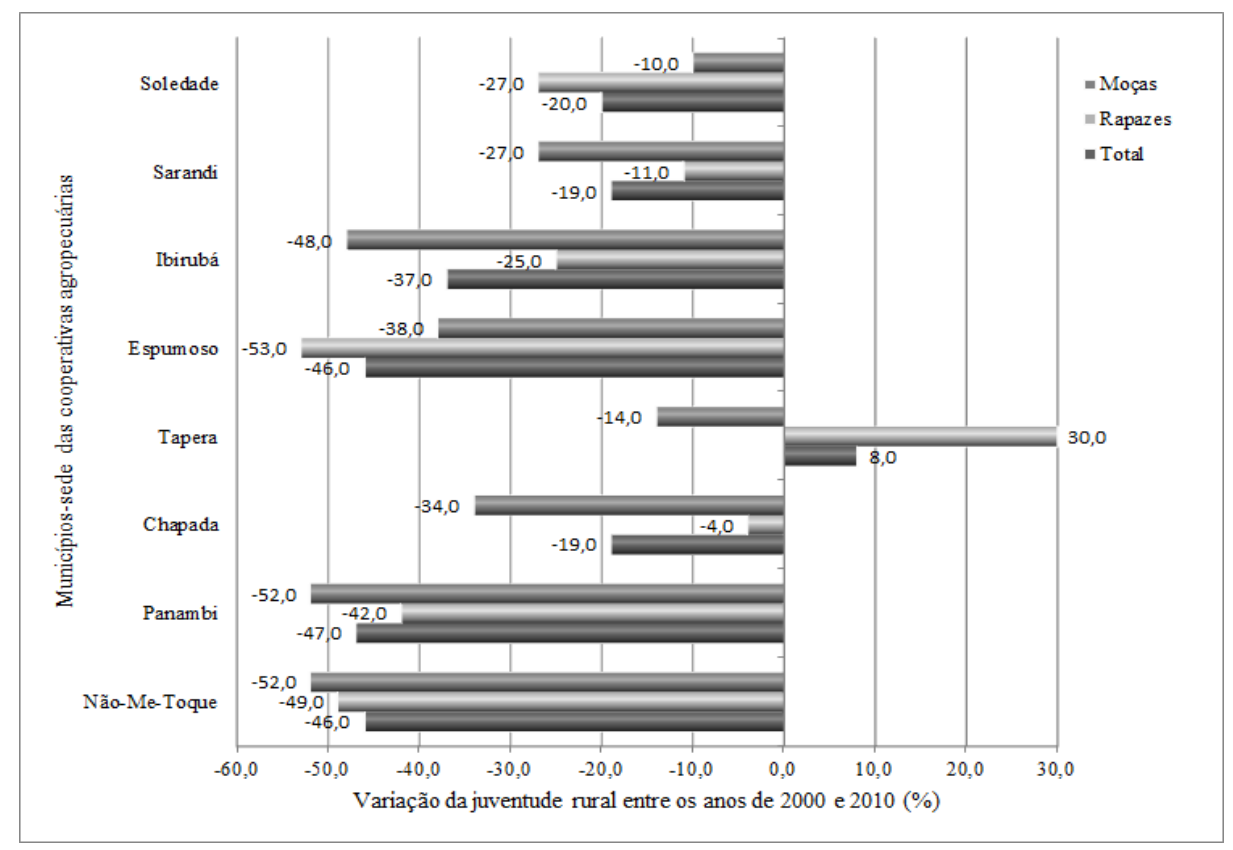

Figura 02 - Variação (\%) da população de jovens rurais nos municípios-sede das cooperativas agropecuárias entre os anos 2000 e 2010.

Fonte: elaboração das autoras com base nos dados do IBGE (2000; 2010).

A Figura 02 evidencia redução entre os jovens rurais na maioria dos municípios considerados. As reduções mais significativas foram encontradas em Panambi - sede da COTRIPAL $(-47,0 \%)$-, Não-Me-Toque - sede da COTRIJAL (-46,0\%) -, e Espumoso - sede da COTRIEL (-46,0\%). Esses números se devem à atração oriunda das indústrias urbanas sobre os jovens rurais nesses municípios, entre outras condicionantes socioeconômicas. Somente em Tapera - sede da COTRISOJA -, ocorreu elevação entre os jovens residentes nas áreas rurais.

Além disso, a Figura 02 também evidencia como as moças são as maiores responsáveis pelos índices de redução. Nos oito municípios considerados ocorreu redução entre as moças rurais 
e em seis essa redução se mostrou maior em relação ao decréscimo entre os rapazes. Somente em Espumoso (sede da COTRIEL) e Soledade (sede da COAGRISOL) a redução entre os rapazes rurais se sobressaiu.

Frente a isso, nota-se como a crise sucessória é um sério embaraço às cooperativas agropecuárias estudadas. Assim, a sucessão vem sendo considerada com atenção em muitas dessas organizações, ao contrário das constatações de Rosa e Silva (2010) em estudo sobre uma cooperativa agropecuária no estado do Paraná.

As motivações das cooperativas agropecuárias do Alto Jacuí sobre a sucessão na agricultura familiar são traduzidas não somente através do receio, mas, também, da intimidade de seus representantes com a temática. Quando indagados sobre as condicionantes socioeconômicas relativas ao cenário de crise sucessória, os representantes indicaram condicionantes coincidentes com as constantes na literatura científica recente, citando a desvalorização do meio rural e da condição de agricultor - como mostrado no estudo de Spanevello, Azevedo, Vargas \& Matte (2011); a situação econômica instável - destacada no estudo de Facioni e Pereira (2015); as relações familiares intrincadas, elucidadas também no trabalho de Spanevello, Azevedo, Vargas \& Matte (2011); a inexistência de autonomia às novas gerações, citada em Matte, Spanevello \& Andreatta (2015); a escolaridade restrita nas áreas rurais, também destacada no estudo de Matte, Spanevello \& Andreatta (2015); entre outras, internas e externas aos estabelecimentos agropecuários familiares.

Essas nuances encontram-se nos recortes das entrevistas destacados a seguir: "Um dos grandes problemas é o pai dizendo que sofre demais para produzir, que o trabalho é degradante, que ele jamais quer aquilo para o filho dele [...]" (Representante COTRIEL); "Dizer que a atividade agrícola não tem renda é uma grande besteira, a atividade agrícola conduzida com capacidade, com orientação técnica, com conhecimento técnico, com tecnologia, hoje, é uma das maiores possibilidades de agregação de renda que se tem [...]" (Representante COTRIEL); "A falta de diálogo é o que alimenta grande parte dos conflitos na hora de definir como vai ser feita a sucessão, seja a empresa familiar rural ou urbana. Isso é geral [...]" (Representante COTRIJAL); "Se o jovem tiver autonomia ele fica, ele procura ficar, até porque o pai diz: 'tu cuida do aviário que tu vai ganhar x por mês' [...]" (Representante COAGRISOL); "Não é porque você mora no meio rural que você não possa fazer uma faculdade e retornar para a atividade, não é por isto que você não pode cursar um curso técnico e voltar para a propriedade [...]" (Representante COTRIEL).

Embora tenham conhecimento sobre as condicionantes socioeconômicas envolvidas nessa crise sucessória vivenciada nas áreas rurais de inserção de suas organizações, os representantes entrevistados asseguraram a existência de inúmeras dificuldades em "manusear" essas condicionantes frente aos jovens rurais, considerando as singularidades de cada estabelecimento agropecuário familiar. Ou seja, cada situação é única. Assim, não existe estratégia fixa destinada a transformar jovens rurais em sucessores.

Nesse sentido, a maior restrição indicada consiste em encontrar mecanismos realmente eficientes, capazes não somente de incentivar a residência nas áreas rurais, mas também o trabalho na agricultura, ou seja, mecanismos auxiliares à concretização da sucessão na agricultura familiar. Esse desafio é sintetizado no relato do representante da COTRIEL, abaixo destacado.

Uma coisa é você motivar o jovem que vai ficar na propriedade trabalhar com a cooperativa, isso é mais fácil. Outra coisa é você fomentar que ao invés de sair quinze jovens do meio rural, saiam só cinco, seis, um, dois. Esta é a grande 
dificuldade! Esta é a 'coisa' que a gente não consegue 'dar a liga', não consegue 'tocar para frente' (Representante COTRIEL).

Dessa maneira, das oito cooperativas agropecuárias estudadas somente COTRIPAL, COTRIJAL, COTRISAL e COAGRISOL tem conseguido realizar ações auxiliares à sucessão, de maneira direta ou indireta. As demais, embora motivadas, ainda se encontram executando ações variadas, sem ênfase sobre a sucessão na agricultura familiar.

4.2 Ações desenvolvidas pelas cooperativas agropecuárias com vistas à sucessão na agricultura familiar

Como mencionado anteriormente, somente às organizações COTRIPAL, COTRIJAL, COTRISAL e COAGRISOL evidenciaram ações auxiliares à sucessão na agricultura familiar. Embora suaves, essas ações são exercidas exatamente sobre as condicionantes socioeconômicas envolvidas na sucessão. Dessa maneira, as mesmas evidenciaram inclinação a interferir, incentivando a manutenção dos jovens cooperados e jovens filhos de cooperados no âmbito do meio rural e da agricultura. De acordo com Spanevello e Lago (2006), a influência exercida através das ações das cooperativas agropecuárias sobre a sucessão está relacionada com a capacidade das mesmas em atender as necessidades dos jovens rurais.

Na COTRIPAL as ações consistem em "núcleo de jovens" e "incentivos à formação técnica agropecuária". O núcleo de jovens envolve uma série de ações sociais, como recreações, esportes, oficinas, teatros, bailes, concursos de beleza (com o intuito de valorizar as moças rurais), realizados anualmente. Também envolvem algumas ações voltadas ao âmbito econômico, como cursos profissionalizantes e palestras técnicas, entre outras. As ações vinculadas ao núcleo de jovens atuam sobre lazer, valorização do meio rural e da condição de agricultor, situação econômica e eficiência técnica do estabelecimento agropecuário familiar. Os critérios de inserção do núcleo de jovens consistem em ser associado ou filho de associado da COTRIPAL e residir em áreas rurais.

Já os incentivos à formação técnica agropecuária consistem na concessão de bolsas de estudo aos filhos de cooperados interessados na formação de Técnico Agropecuário. Nesse sentido, a organização fomenta a escolarização dos jovens rurais. Contudo, os incentivos somente são concedidos com as assertivas dos jovens rurais em retornarem aos estabelecimentos agropecuários familiares e utilizar nos mesmos os conhecimentos oriundos do curso técnico.

$\mathrm{Na}$ COTRIJAL as ações são intituladas "líderes mirins", "participação em família" e "novas gerações". Líderes mirins é uma ação voltada à valorização do trabalho na agricultura e da vida no meio rural através do cooperativismo. Essa ação envolve crianças e adolescentes, filhos de cooperados da COTRIJAL, mobilizados através de atividades lúdicas.

Já a ação conhecida como participação em família envolve não somente os cooperados da COTRIJAL, normalmente do sexo masculino, mas também seus familiares. Essa ação visa a criação de vínculos entre as famílias rurais associadas e a organização, facilitando o diálogo entre as mesmas, ouvindo todos os seus integrantes, incluindo os jovens - futuros sucessores.

Por fim, a ação voltada às novas gerações visa nomeadamente os futuros sucessores dos estabelecimentos agropecuários cooperados. Essa ação é desenvolvida em módulos temáticos com o intuito de estimular a integração dos jovens ao trabalho na agricultura. Não obstante, visa enfatizar a discussão da temática da sucessão, convidando, ocasionalmente, os demais familiares a integrar os trabalhos. 
Na COTRISAL as ações consistem em "seminário de jovens rurais", "encontro de líderes" e "estágios e bolsas de estudo". O seminário de jovens rurais é realizado anualmente com o auxílio de outras organizações voltadas ao meio rural e à agricultura, como a Empresa de Assistência Técnica e Extensão Rural (EMATER). Esse seminário envolve jovens rurais em idade escolar e aborda assuntos variados com o intuito de disseminar informações relevantes.

O encontro de líderes visa a valorização das famílias rurais e sua integração com a COTRISAL, envolvendo não somente os homens, mas também mulheres e, sobretudo, jovens de ambos os sexos. Já os estágios e bolsas de estudo consistem em certas regalias direcionadas aos jovens rurais, filhos de agricultores cooperados à COTRISAL. Esses contam com descontos nas mensalidades de graduações cursadas em universidades conveniadas e também são incentivados a realizar estágios na COTRISAL.

Por fim, na COAGRISOL as ações são intituladas "escola no campo", "gestão rural para estudantes" e "festa do agricultor". A ação escola no campo é desenvolvida em conjunto com fornecedores de insumos e envolve crianças rurais do Ensino Fundamental. A ação envolve atividades lúdicas voltadas à valorização da agricultura e do meio rural. Quanto a essa ação, fica a indagação: não seria somente uma estratégia de marketing e comercialização dos fornecedores de insumos?

Já a ação conhecida como gestão rural destinada a estudantes é realizada em conjunto com o Serviço Nacional de Aprendizagem do Cooperativismo do Estado do Rio Grande do Sul (SESCOOP/RS). É um curso com intuito de desenvolver conceitos e técnicas de gestão para serem utilizadas nas atividades desenvolvidas nos estabelecimentos agropecuários dos cooperados. Essa ação é realizada com adolescentes rurais, filhos de agricultores cooperados, do último ano do Ensino Fundamental.

A festa do agricultor é realizada anualmente e conta com o auxílio de outras organizações voltadas ao meio rural. 0 último evento realizado contou com mais de 300 pessoas. Para essa festa são convidados todos os membros das famílias rurais associadas, envolvidos em diversas atividades lúdicas. Além de funcionar como uma atividade de lazer, também atua na valorização da agricultura e do meio rural.

Dentre essa série de ações, chamam a atenção a "núcleo de jovens" da COTRIPAL e a "novas gerações" da COTRIJAL. Embora de maneira diferente, ambas as ações mostraram-se as mais compatíveis com a realidade da sucessão na agricultura familiar: a COTRIPAL tem investido em atividades intensas e diversas com o intuito de cativar indiretamente os jovens rurais e a COTRIJAL tem tratado diretamente do tema da sucessão, trazendo as famílias rurais inteiras ao diálogo.

4.3 Resultados alcançados com as ações cooperativistas voltadas à sucessão na agricultura familiar

Os jovens rurais vinculados com as cooperativas agropecuárias consideram as mesmas como organizações indispensáveis ao trabalho na agricultura e à vida no meio rural, como mostraram os relatos: "Considero a cooperativa como o melhor espaço para quem precisa produzir" (Jovem rural da COAGRISOL); "Gostar da atividade, ter apoio da família e ter as ações da cooperativa é fundamental pra permanecer no campo" (Jovem rural da COTRIPAL). Esses resultados vão de encontro aos obtidos por Rosa e Silva (2010), no Paraná, onde a maioria dos 
cooperados da Cooperativa Agroindustrial Vale do Ivaí Ltda. (COOPERVAL) concluiu a relevância da cooperativa agropecuária na estabilidade socioeconômica de seus futuros como agricultores.

Contudo, as ações citadas anteriormente, consideradas como auxiliares à sucessão, não foram visualizadas com muita relevância entre os entrevistados. Na realidade, os jovens rurais reconheceram maior incentivo ao seu estabelecimento como sucessores nas ações de cunho técnico tradicionais das cooperativas agropecuárias, envolvendo a atuação de engenheiros agrônomos e médicos veterinários. De acordo com Spanevello e Lago (2006), ações relacionadas à assistência técnica gratuita são um dos grandes atributos dessas organizações. Dessa maneira, o vínculo entre os jovens rurais e as cooperativas agropecuárias se deve aos técnicos.

Os técnicos são formadores de opinião. Ele entusiasma você em relação à cooperativa. Qual produtor não gostaria de ter um gerente da unidade, um agrônomo, um técnico, tomando um mate contigo e discutindo a questão da produtividade que é uma coisa que te motiva, que te entusiasma. Por isso, os técnicos podem contribuir diretamente com a sucessão (Jovem rural da COTRIJAL).

Essa ênfase concedida às ações de cunho técnico se deve, inclusive, aos maiores investimentos das cooperativas agropecuárias nesse âmbito, secundarizando as ações de cunho socioeconômico, como as descritas anteriormente. Em somatório, as ações auxiliares à sucessão ainda não gozam da consistência das ações técnicas: suas metodologias são rudimentares e descontínuas, ainda consideradas "experimentais". Além disso, é prudente recordar a predominância de jovens rurais do sexo masculino entre os entrevistados, o que também pode ter influenciado sobre o maior reconhecimento das ações de cunho técnico.

Embora as ações voltadas a auxiliar a sucessão abordem condicionantes socioeconômicas consideradas limitantes, ainda são encontradas lacunas entre os anseios dos jovens rurais e das cooperativas agropecuárias. Isso acontece devido à heterogeneidade da agricultura familiar e à diversidade da juventude rural: esses atributos não consentem a elaboração de metodologias singulares e inflexíveis. Logo, ações consideradas úteis à sucessão em determinados estabelecimentos agropecuários, não necessariamente surtirão efeito em outros, dado a esses atributos.

Apesar das dificuldades encontradas na saga das cooperativas agropecuárias em prol da sucessão dos estabelecimentos agropecuários de seus agricultores cooperados, foram visualizados alguns resultados favoráveis, como o tímido aumento do número de jovens rurais cooperados, dado os incentivos das cooperativas agropecuárias em sua instalação como agricultores independentes. Mas como as ações cooperativistas voltadas à sucessão são recentes, outros resultados futuros ainda são esperados.

\section{CONCLUSÕES}

Em síntese, o estudo evidenciou os esforços das cooperativas agropecuárias em contribuir com a sucessão dos estabelecimentos de seus cooperados, incentivando os jovens cooperados e jovens filhos de cooperados a residir no meio rural e trabalhar na agricultura.

Esses esforços remetem à necessidade de renovação dos cooperados dessas organizações: sinônimo de sua sobrevivência. Novas gerações de agricultores residindo no meio rural e trabalhando na agricultura favorecem o surgimento de novas gerações de agricultores vinculados com as cooperativas agropecuárias. 
Embora as cooperativas agropecuárias estudadas tenham demonstrado intimidade com a temática da sucessão, as mesmas têm encontrado muitas dificuldades em organizar ações nesse sentido, devido à heterogeneidade da agricultura familiar e à diversidade da juventude rural. Nesse sentido, nem todas as cooperativas agropecuárias têm conseguido realizar ações direcionadas à sucessão.

Nas organizações onde essas ações existem, embora suaves, as mesmas estão voltadas a atender as mais diversas necessidades dos jovens rurais, envolvendo condicionantes socioeconômicas consideradas limitantes à sucessão, como renda, autonomia, relacionamento intrafamiliar, valorização do trabalho na agricultura e da vida no meio rural, escolarização, entre outros.

Contudo, mesmo reconhecendo a contribuição das cooperativas agropecuárias na sucessão, os jovens rurais ainda tendem a valorizar mais as ações de cunho técnico tradicionais, com a atuação de engenheiros agrônomos e médicos veterinários. Isso indica a existência de fragilidades nas demais ações de cunho socioeconômico, cujas metodologias ainda são rudimentares e descontínuas. Ainda assim, algumas organizações visualizaram incremento no número de cooperados, sendo esse um indicativo da concretização da sucessão em estabelecimentos agropecuários, levando novos agricultores a voltarem-se às cooperativas. Tendo em vista o caráter "experimental" das ações desenvolvidas em favor da sucessão, as organizações esperam ainda mais resultados no futuro, na medida em que essas ações forem aprimoradas.

Dessa maneira, embora não somente as cooperativas agropecuárias sejam contribuintes na sucessão dos estabelecimentos agropecuários, as mesmas evidenciam relevante reforço à continuidade das novas gerações de agricultores familiares no meio rural e na agricultura. Contudo, não se deve deixar a encargo somente dessas organizações a responsabilidade pela sucessão. Embora sua contribuição seja relevante, não deve ser exclusiva, tendo em vista a complexidade e delicadeza da realidade da agricultura familiar e da juventude rural brasileira.

\section{REFERÊNCIAS}

Abramovay, R. (Org.). (1998). Juventude e agricultura familiar: desafios dos novos padrões sucessórios. Brasília: Unesco.

Bardin, L. (2011). Análise de conteúdo. São Paulo: Edições 70.

Bialoskorski Neto, S. (2007). Um ensaio sobre desempenho econômico e participação em cooperativas agropecuárias. Revista de Economia e Sociologia Rural, 45 (1), 119-138. Disponível em: $\quad$ http://www.scielo.br/scielo.php?script=sci arttext\&pid=S010320032007000100006.

Boessio, A. T. (2015). Jovens rurais e processos de sucessão: em análise uma cooperativa agropecuária no triângulo mineiro. Dissertação de Mestrado, Universidade Federal de Viçosa, Viçosa, MG, Brasil.

Bourdieu, P. (2011). Las estrategias de la reproducción social. Buenos Aires: Siglo Veintiuno Editores.

Bourdieu, P. (2012a). Uma vida perdida. In: Bourdieu, P. (Org.). A miséria do mundo (pp. 437-441). Petrópolis: Vozes.

Bourdieu, P. (2012b). As contradições da herança. In: Bourdieu, P. (Org.). A miséria do mundo (pp. 587-593). Petrópolis: Vozes.

Brumer, A. (2004). Gênero e agricultura: a situação da mulher na agricultura do Rio Grande do Sul. 
Estudos Feministas, 12(1), 205-227. Disponível em: http://www.scielo.br/pdf/ref/v12n1/21699.

Camarano, A. A., \& Abramovay, R. (1998). Êxodo rural, envelhecimento e masculinização no Brasil: panorama dos últimos cinquenta anos. Revista Brasileira de Estudos de População, 5(2), 4565. Disponível em:www.rebep.org.br/index.php/revista/article/download/404/pdf 380.

Carneiro, M. J. (1999). O ideal rurbano: campo e cidade no imaginário dos jovens rurais. In: Silva, F. C. T., Santos, R., \& Costa, L. F. C. (Orgs.). Mundo rural e política: ensaios interdisciplinares (pp. 97-117). Rio de Janeiro: Campus.

Castro, E. G. (2009). Juventude rural no Brasil: processos de exclusão e a construção de um ator político. Revista Latinoamericana de Ciencias Sociales, Ninez y Juventud, 7(1), 179-208. Disponível

em:

http://www.scielo.org.co/scielo.php?pid=S1692715X2009000100008\&script=sci arttext.

Champagne, P. (1986). La reproduction de I'identité. Actes de la Recherche en Sciences Sociales, (65), 41-64. Disponível em: http://www.persee.fr/doc/arss 033553221986 num 6512349.

Drebes, L. M. (2014). Projeto de juventude rural, campo de possibilidade e migrações: um estudo documental do Centro de Desenvolvimento do Jovem Rural (CEDEJOR). Revista Monografias Ambientais, 13(5), 4087-4098. Disponível em: http://cascavel.ufsm.br/revistas/ojs2.2.2/index.php/remoa/article/view/15036.

Facioni, D., \& Pereira, M. W. G. (2015). Análise dos determinantes da sucessão em assentamento rural no estado de Mato Grosso do Sul. Organizações Rurais \& Agroindustriais, 17(1), 119-136. Disponível em: http://www.redalyc.org/pdf/878/87838281010.pdf.

Gaviria, M. R., \& Menasche, R. (2006). A juventude rural no desenvolvimento territorial: análise da posição e do papel dos jovens no processo de transformação do campo. Estudo e Debate, 13(1), 69-82. Disponível em: http://www6.ufrgs.br/pgdr/arquivos/526.pdf.

Gil, A. C. (2011). Métodos e técnicas de pesquisa social. São Paulo: Editora Atlas.

Ibge. (2000). Censo Demográfico 2000. Base de Dados. Sem local: IBGE. Disponível em: http://www.ibge.gov.br.

Ibge. (2010). Censo Demográfico 2010. Base de Dados. Sem local: IBGE. Disponível em: http://www.ibge.gov.br.

Lamarche, H. (1993). A agricultura familiar: comparação internacional - uma realidade multiforme. Campinas: Editora UNICAMP.

Leitzke, V. W., \& Santos, V. Z. (2013). Juventude Rural e Inclusão do Jovem na Gestão de Cooperativas da Economia Solidária, no Nordeste do RS. In: Cotrim, D. S (Org.). Gestão de cooperativas: produção acadêmica da Ascar. (pp. 316-330). Porto Alegre: EMATER/RS-ASCAR.

Matte, A., Spanevello, R. M., \& Andreatta, T. (2015). Perspectivas de sucessão em propriedades de pecuária familiar no município de Dom Pedrito - RS. Holos, 1(31), 144-159. Disponível em: http://www2.ifrn.edu.br/ojs/index.php/HOLOS/article/view/1964.

Poupart, J., Deslauriers, J. P., Groulx, L. H., Laperrière, A., Mayer, R., \& Pires, A. P.(Org.). (2010). A pesquisa qualitativa: enfoques epistemológicos e metodológicos. Petrópolis: Editora Vozes.

Renk, A., \& Cabral, V. (2002). Campesinidade e migração internacional: novas estratégias dos jovens rurais do Oeste Catarinense. Revista Esboços, 10(10), 09-28. Disponível em: https://periodicos.ufsc.br/index.php/esbocos/article/view/385.

Rosa, C. I. L. F., \& Silva, O. H. (2010). Sucessão familiar e cooperativismo: o caso da cooperativa COOPERVAL. Revista NUPEM, 2(2), 177-187. Disponível em: http://www.fecilcam.br/revista/index.php/nupem/article/view/129. 
Silvestro, M. L. (Org.). (2001). Os impasses sociais da sucessão hereditária na agricultura familiar. Florianópolis: Epagri; Brasília: NEAD/MDA.

Spanevello, R. M., \& Lago, A. (2006). As cooperativas agropecuárias e a sucessão profissional na agricultura familiar. Anais do Congresso da Sociedade Brasileira de Economia, Sociologia e Administração Rural, Londrina, PR, Brasil, 45. Disponível em: www.sober.org.br/palestra/6/1001.

Spanevello, R. M. (2008). A dinâmica sucessória na agricultura familiar. Tese de Doutorado, Universidade Federal do Rio Grande do Sul, Porto Alegre, RS, Brasil.

Spanevello, R. M., Azevedo, L. F., Vargas, L. P., \& Matte, A. (2011). A migração juvenil e implicações sucessórias na agricultura familiar. Revista de Ciências Humanas, 45(2), 291-304.

Stropassolas, V. L. (2003). O movimento (migratório) da juventude rural: em busca do reconhecimento social e da cidadania. Revista Grifos, (14), 147-167.

Weisheimer, N. (2009). A situação juvenil na agricultura familiar. Tese de Doutorado, Universidade Federal do Rio Grande do Sul, Porto Alegre, RS, Brasil. 